\title{
Seasonal and inter-annual variations in troposphere-to-stratosphere transport from the tropical tropopause layer
}

\author{
J. G. Levine ${ }^{1, *}$, P. Braesicke ${ }^{1,2}$, N. R. P. Harris ${ }^{1,3}$, and J. A. Pyle ${ }^{1,2}$ \\ ${ }^{1}$ Centre for Atmospheric Science, Department of Chemistry, University of Cambridge, Cambridge, UK \\ ${ }^{2}$ Atmospheric Chemistry Modelling Support Unit, National Centre for Atmospheric Science, University of Cambridge, \\ Cambridge, UK \\ ${ }^{3}$ European Ozone Research Coordinating Unit, University of Cambridge, Cambridge, UK \\ * now at: the British Antarctic Survey, Cambridge, UK
}

Received: 16 November 2007 - Published in Atmos. Chem. Phys. Discuss.: 10 January 2008

Revised: 10 June 2008 - Accepted: 11 June 2008 - Published: 10 July 2008

\begin{abstract}
In an earlier study of troposphere-to-stratosphere transport (TST) via the tropical tropopause layer (TTL), we found that the vast majority of air parcels undergoing TST from the base of the TTL enter the extratropical lowermost stratosphere quasi-horizontally and show little or no regional preference with regards to origin in the TTL or entry into the stratosphere. We have since repeated the trajectory calculations - originally limited to a single Northern Hemisphere winter period - in a variety of months and years to assess how robust our earlier findings are to change of timing. To first order, we find that the main conclusions hold, irrespective of the season, year and phase of the El Niño Southern Oscillation (ENSO). We also explore: the distribution of TST between the Northern and Southern Hemispheres; the sensitivity of modelled TST to the definition of the tropopause; and the routes by which air parcels undergo transport exclusively to the stratospheric overworld. Subject to a dynamical definition of the tropopause, we identify a strong bias towards TST in the Southern Hemisphere, particularly during the Northern Hemisphere summer. The thermal tropopause, defined according to the World Meteorological Organization, lies above the dynamical tropopause throughout the extratropics. Inevitably, on switching to the thermal definition, we calculate much less transport across the tropopause, particularly in the subtropics, which could be important with regards to interpretation of processes affecting ozone chemistry in the extratropical lowermost stratosphere (ELS). In contrast to the rather homogeneous nature of TST into the ELS, we
\end{abstract}

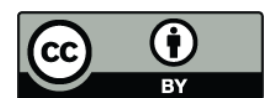

Correspondence to: J. G. Levine (javi@bas.ac.uk) find that transport to the overworld takes place from relatively well-defined regions of the TTL, predominantly above the West Pacific and Indonesia, except for an El Niño period in which most transport takes place from regions above the East Pacific and South America.

\section{Introduction}

In a recent study (Levine et al., 2007), we used trajectory calculations to investigate the routes by which air parcels undergo troposphere-to-stratosphere transport (TST) from the base of the tropical tropopause layer (TTL), during a baseline Northern Hemisphere winter period (January 2001). The motivation for the study stemmed from the potential for halogenated very short-lived species, lifted rapidly as far as the base of the TTL (e.g. by convection), to reach the stratosphere, where they could contribute to the depletion of ozone. One of the main findings of our earlier model study was that the vast majority of air parcels, approximately $85 \%$, which undergo TST on short timescales (less than or equal to four weeks), enter the extratropical lowermost stratosphere (ELS), that part of the stratosphere which lies below $380 \mathrm{~K}$ in potential temperature, by quasi-isentropic transport across the subtropical tropopause. This challenges the tacit assumption that TST mainly takes place into the overworld, that part of the stratosphere which lies above $380 \mathrm{~K}$. We also found that TST from the base of the TTL (transport into the overworld and ELS) was remarkably homogeneous, with a similar fraction of air undergoing TST from each longitudinal region of the TTL to each longitudinal region of the stratosphere.

Published by Copernicus Publications on behalf of the European Geosciences Union. 
The main aim of the work presented here is to determine to what extent our earlier findings, based on trajectory calculations in January 2001, prove robust to change of season, year and phase of the El Niño Southern Oscillation (ENSO). To this end, the calculations are extended to each remaining month of 2001 and a selection of months in 1998 and 1999. As in previous studies (e.g. Fueglistaler et al., 2004), we take 2001 as a baseline twelve-month period that is relatively unperturbed by the ENSO, as evidenced by the relatively small values of the multivariate ENSO in$\operatorname{dex}(-1.2<\mathrm{MEI}<1.4)$. Through calculations in a variety of months in 2001, we investigate seasonal variations in TST in the absence of a strong ENSO influence. In contrast, we examine inter-annual variations, including those related to the ENSO, by comparing the results to 2001 with those obtained from calculations in 1998 and 1999; the NH winters of $1997 / 1998$ and 1998/1999 have previously been identified as El Niño (MEI > 1.4) and La Niña (MEI $<-1.2)$ respectively (see e.g., Bonazzola and Haynes, 2004). Besides changing the timing of the experiment, in an extension of our earlier work, we compare how much TST takes place in the Northern and Southern Hemispheres, and explore the sensitivity of modelled TST to the definition of the tropopause (see later).

Recent model studies of TST have implicitly studied transport to the overworld (e.g. Hatsushika and Yamazaki, 2003; Bonazzola and Haynes, 2004; Fueglistaler et al., 2004 and 2005), usually in an effort to explain the very low water vapour mixing ratios observed in the tropical lower stratosphere (see e.g., Mote et al., 1995 and 1996). There have been relatively few model studies of transport from the TTL into the ELS (Chen, 1995; Berthet et al., 2007) despite recognition of its potential importance (e.g. Allam and Tuck, 1984; Holton et al., 1995) and observational evidence of its effects on the chemical composition of the mid-latitude lower stratosphere (e.g. Vaughan and Timmis, 1998; O'Connor et al., 1999). However, trace gas observations in the lowermost stratosphere have been used to infer seasonal variations in the amount of TST into the ELS (see Randel et al., 2001; Prados et al., 2003; Hoor et al., 2004 and 2005), where an increase in the concentration of water vapour or carbon monoxide, accompanied by a decrease in the concentration of ozone, is indicative of an increase in TST. Here, as in our earlier study, we explore TST from the base of the TTL, including transport into the ELS and overworld. However, for comparison with previous studies, we will also briefly examine the routes by which air parcels undergo transport exclusively to the overworld.

Some studies of the ENSO have investigated its effect on the chemical composition of the troposphere, including the tropospheric ozone column and the concentration of water vapour in the tropical upper troposphere (e.g. Chandra et al., 1998; Ziemke and Chandra, 2003). However, more recently, the effects of the ENSO on the transport of tropospheric water vapour into the overworld (e.g. Hatsushika and Yamazaki, 2003; Bonazzola and Haynes, 2004) and the transport of stratospheric ozone into the troposphere (e.g. Zeng and Pyle, 2005) have been investigated. The findings of these studies suggest that the ENSO not only affects the vertical distribution of trace gases within the troposphere, but also the transport of trace gases between the troposphere and the stratosphere. We will explore what effect the ENSO has on the routes by which air parcels undergo TST from the base of the TTL.

Levine et al. (2007) investigated TST with respect to the dynamical tropopause, defined throughout the extratropics as the level at which the potential vorticity, PV, is equal to $2 \mathrm{PV}$ units, above which the concentration of ozone is observed to increase rapidly towards typically stratospheric values (see e.g., Hegglin et al., 2006; Thouret et al., 2006). Here, we continue to investigate TST using this definition of the tropopause. However, we also assess the sensitivity of modelled TST to the choice of tropopause definition by repeating some of our calculations using the thermal definition of the World Meteorological Organization (WMO, 1957). According to some observations (e.g. Bethan et al., 1996) and theoretical studies (e.g. Wirth, 2000), the thermal tropopause may lie as much as $800 \mathrm{~m}$ above the dynamical tropopause at mid-latitudes. TST calculated with respect to the thermal tropopause could therefore differ from TST calculated with respect to the dynamical tropopause.

In Levine et al. (2007) and in this study, we use forward trajectories to explore the fate of air that has reached the base of the TTL. This approach is different, in concept, to most of the earlier trajectory studies, which used backward trajectories to explore the origin of air reaching the lower stratosphere. Results obtained by the two approaches must be compared with great care. We also note that mass fluxes cannot be calculated by our approach, as it does not account for longitudinal variations in the flux of air through the base of the TTL, or the origin of this air. In our earlier study (Levine et al., 2007), a series of tracer experiments revealed marked variations in the amount of boundary-layer air that enters different longitudinal regions of the TTL.

The trajectory calculations are described in the next section and the results of these calculations are presented in Sect. 3. We examine variations in the amount of TST from the base of the TTL in Sect. 3.1. The routes by which air parcels undergo TST are explored in Sects. 3.2 and 3.4, focussing on latitudinal and longitudinal structure respectively. In Sect. 3.3, we examine the distribution of TST between the Northern and Southern Hemispheres, whilst we explore the sensitivity of modelled TST to the definition of the tropopause in Sect. 3.5. In Sect. 3.6, we examine the routes by which air parcels undergo transport exclusively to the stratospheric overworld (i.e. neglecting transport into the ELS) and we discuss the results, with reference to the literature, in Sect. 4. 


\section{Method}

The trajectory calculations are only described in outline here as they follow precisely the same format as described in Levine et al. (2007). For the purposes of this work, the calculations originally performed in January 2001 are extended to each remaining month of 2001 (February-December) and a selection of months in 1998 and 1999. To capture seasonal variations in 1998 and 1999, it was considered sufficient to repeat the calculations every other month (i.e. in February, April, June, August, October and December). However, we explore a number of additional months, including December 1997, in order to cover, comprehensively, the key meteorological seasons, including the Northern Hemisphere winters of 1997/1998 (El Niño) and 1998/1999 (La Niña).

At the start of each month, the operational analyses of the European Centre for Medium-range Weather Forecasts (ECMWF) are used to calculate the height of the dynamical tropopause as a function of latitude and longitude. Throughout the extratropics, between $\pm(28-90)^{\circ}$ latitude, the tropopause is defined as the level at which the potential vorticity, $\mathrm{PV}$, is equal to $2 \mathrm{PV}$ units. However, in the tropics, between $\pm 13^{\circ}$ latitude, where the PV cannot be used to define the tropopause, the level of minimum temperature, or "cold point", is used instead. To ensure a smooth transition from one definition to the other, a weighted average of the two levels is calculated in the subtropics, between $\pm(13-28)^{\circ}$ latitude, according to Hoerling et al. (1993). The tropopause marks the top of the TTL, spanning approximately $100-200 \mathrm{hPa}$ (roughly $345-385 \mathrm{~K}$ in potential temperature). The trajectories are released in a region close to the base of the TTL, between about 165 and $195 \mathrm{hPa}$ (roughly 345-355 K). In each month, 28800 three-dimensional trajectories are calculated using Offline 3 (see Methven, 1997) from points spaced $1^{\circ}$ apart, between $\pm 19.5^{\circ}$ latitude and 0.5-359.5 longitude, on the upper and lower pressure surfaces that bound this region. For further details on the precise definition of this region, see Levine et al. (2007). The locations of these trajectories are integrated four weeks forward in time, using T106 ECMWF operational analyses, and recorded every $30 \mathrm{~min}$.

The analyses with which the trajectories are calculated describe the flow resolved at a horizontal resolution of approximately $1.1^{\circ} \times 1.1^{\circ}$ and a temporal resolution of $6 \mathrm{~h}$. The trajectories are therefore believed to be reasonably representative of the large-scale ascent observed in the tropics. However, they cannot capture meteorological features occurring on short spatial and/or temporal scales, including individual small-scale convective events, the relative importance of which remains uncertain.

We investigate TST over periods of four weeks, motivated by the need to assess the potential for halogenated very shortlived species to reach the stratosphere. However, in an earlier study (Levine et al., 2007), we showed that the bulk of TST from the base of the TTL (in a single-release tracer ex- periment) is captured within a four-week integration and the variations in the amount of TST from different regions of the TTL are established on, if anything, shorter timescales. The latter were also found to be qualitatively insensitive to the altitude of tracer release in the TTL. On longer timescales, we saw an increase in the relative importance of transport to the overworld, compared to transport into the ELS. For example, we found that the fraction of a TTL tracer transported to the overworld increased from approximately $2 \%$, after four weeks, to roughly $6 \%$, after twelve months. In contrast, the fraction of this tracer found in the ELS peaked after about three weeks, at approximately $12 \%$, and changed little thereafter. Note that, even after twelve months, two thirds of the TTL tracer found in the stratosphere was found in the ELS.

Once the trajectories have been calculated, the analyses are used to identify if, and where, each trajectory enters the stratosphere and, specifically, the stratospheric overworld. Most of the results presented in the next section concern the routes by which air parcels undergo TST (Sects. 3.1-3.5); these are based solely on the trajectories that are found in the stratosphere at the end of the integration (i.e. four weeks after release). Some previous studies (e.g. Wernli and Bourqui, 2002; James et al., 2003) have filtered out air parcels demonstrating shallow TST (i.e. penetrating only a short distance into the stratosphere and/or spending only a short time in the stratosphere before returning to the troposphere), for example, by identifying only those air parcels that spend 9 days or more in the stratosphere as undergoing "significant TST". We have not filtered out air parcels undergoing shallow TST, on the basis that shallow TST could be important in determining the chemical composition of the lowermost stratosphere. Based on a small sample of the trajectories we calculate (those calculated in January and July 2001), 85-90\% of the air parcels we identify as undergoing TST spend a total of 9 days or more in the stratosphere, integrated over a fourweek period. However, only about a quarter spend at least 9 days in the stratosphere upon first crossing the tropopause, implying many of the air parcels we identify as undergoing TST demonstrate shallow TST. We note that shallow TST, in particular, may be influenced by the resolution and quality of the available time-varying meteorological fields. Additional results are presented concerning the routes by which air parcels undergo transport to the overworld (Sect. 3.6), based on the subset of TST trajectories that reach potential temperatures in excess of $380 \mathrm{~K}$; the $380 \mathrm{~K}$ isentrope closely coincides with the tropical cold point.

\section{Results}

\subsection{The fraction of air parcels undergoing TST}

Figure 1 illustrates the fraction of air parcels released at the base of the TTL in each month of 2001, 1998 and 1999, which are found in the stratosphere (subdivided into 


\section{Fraction of air parcels found in the}

stratosphere 4 weeks after release
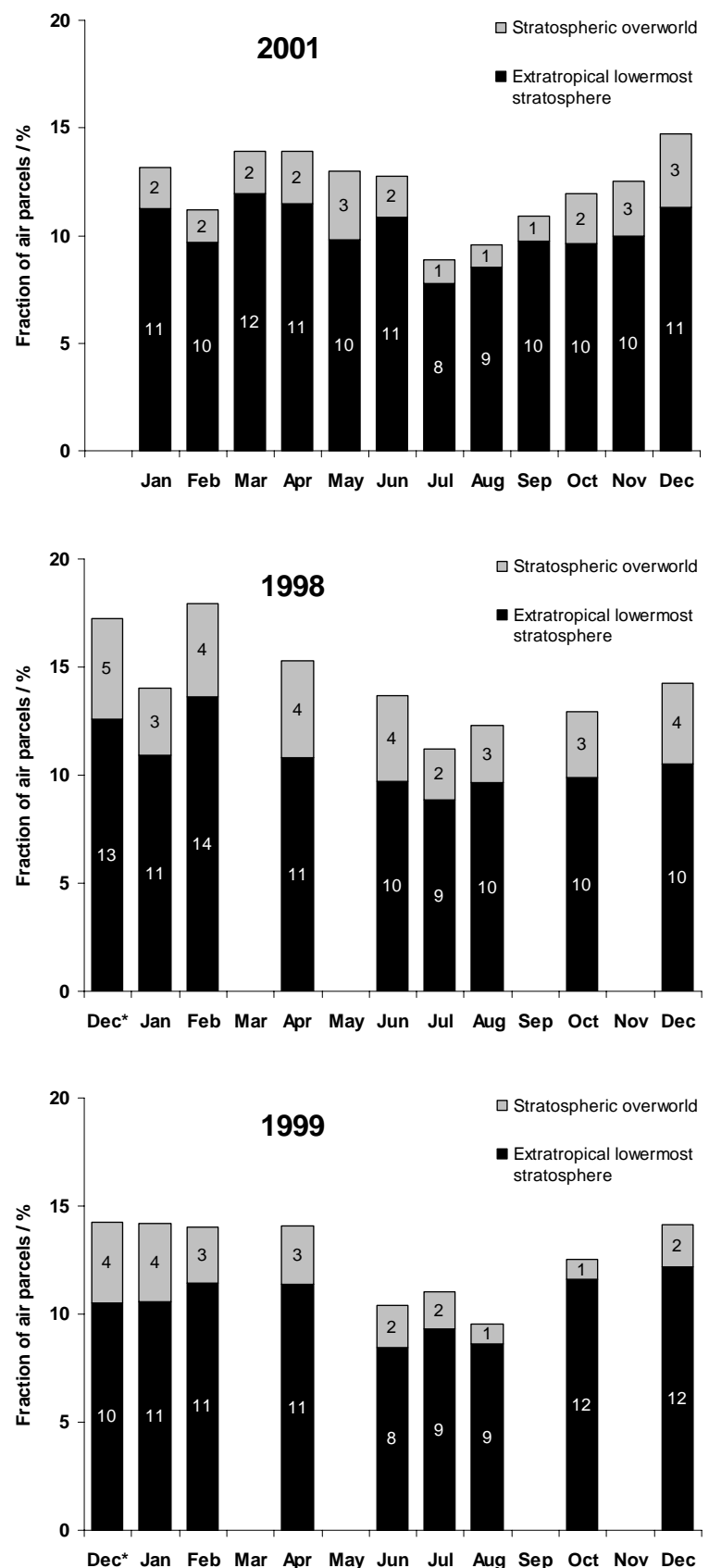

Fig. 1. The fraction of air parcels released at the base of the TTL in each month of 2001 (baseline), 1998 (El Niño) and 1999 (La Niña) that are found in the stratosphere (subdivided into the stratospheric overworld and the extratropical lowermost stratosphere) four weeks later. NB Not all months in 1998 (middle panel) or 1999 (lower panel) were studied, however, the results for the preceding December (i.e. December 1997 and December 1998; labelled Dec*) are presented. the stratospheric overworld and the extratropical lowermost stratosphere; ELS) four weeks later. We present the results for 2001 first (top panel) as this "baseline" year is relatively unperturbed by the ENSO. As discussed in Sect. 1, 1998 (middle panel) and 1999 (lower panel) include El Niño and La Niña periods respectively. Note that, for 1998 and 1999, the results for the preceding December (i.e. December 1997 and December 1998; labelled Dec*) are also included.

Irrespective of the season and year, many more air parcels are found in the ELS than are found in the overworld at the end of each four-week integration. Indeed, averaged over the whole of 2001, five times as many air parcels are found in the ELS (roughly $10 \%$ of those released) as are found in the overworld (about $2 \%$ ). It would appear therefore that one of the major findings of our earlier study (Levine et al., 2007) proves robust to change of timing: the majority of air parcels undergoing TST from the base of the TTL undergo transport into the ELS.

The total fraction of air transported to the stratosphere (overworld + ELS) appears to exhibit an annual cycle between a maximum in the Northern Hemisphere $(\mathrm{NH})$ winter and a minimum in the $\mathrm{NH}$ summer. Broadly speaking, it would appear that both the fraction of air transported to the overworld and the fraction of air transported into the ELS exhibit the same seasonality. As for variations between years, more TST, particularly transport to the overworld, takes place at the beginning of 1998 (El Niño) than at the beginning of either 2001 (baseline) or 1999 (La Niña). However, a longer multi-annual study (e.g. Fueglistaler et al., 2005) is required to assess the statistical significance of the link between an El Niño and an increase in TST.

\subsection{The latitudinal structure of TST}

Figure 2 illustrates what fraction of the air parcels undergoing TST in each month of 2001, 1998 and 1999 enter the stratosphere in the tropics between $\pm 15^{\circ}$ latitude, the subtropics between $\pm(15-35)^{\circ}$ latitude, and at higher latitudes between $\pm(35-90)^{\circ}$ latitude. Note that the temporal variations in the absolute number of air parcels undergoing TST (discussed in the previous section) have been removed. Irrespective of the season and year, the vast majority of air parcels undergoing TST, between 70 and $90 \%$, enter the stratosphere in the subtropics, whilst the remainder are roughly evenly split between the tropics and higher latitudes. The fraction of air parcels entering the stratosphere at higher latitudes is relatively small but appears to be greater in July and August than at any other time of the year. Additionally, TST at higher latitudes appears to play a somewhat greater part in 1999 (La Niña) than 2001 (baseline) or 1998 (El Niño). However, the statistical significance of these variations has yet to be assessed. 


\section{Latitudes at which air parcels enter} the stratosphere
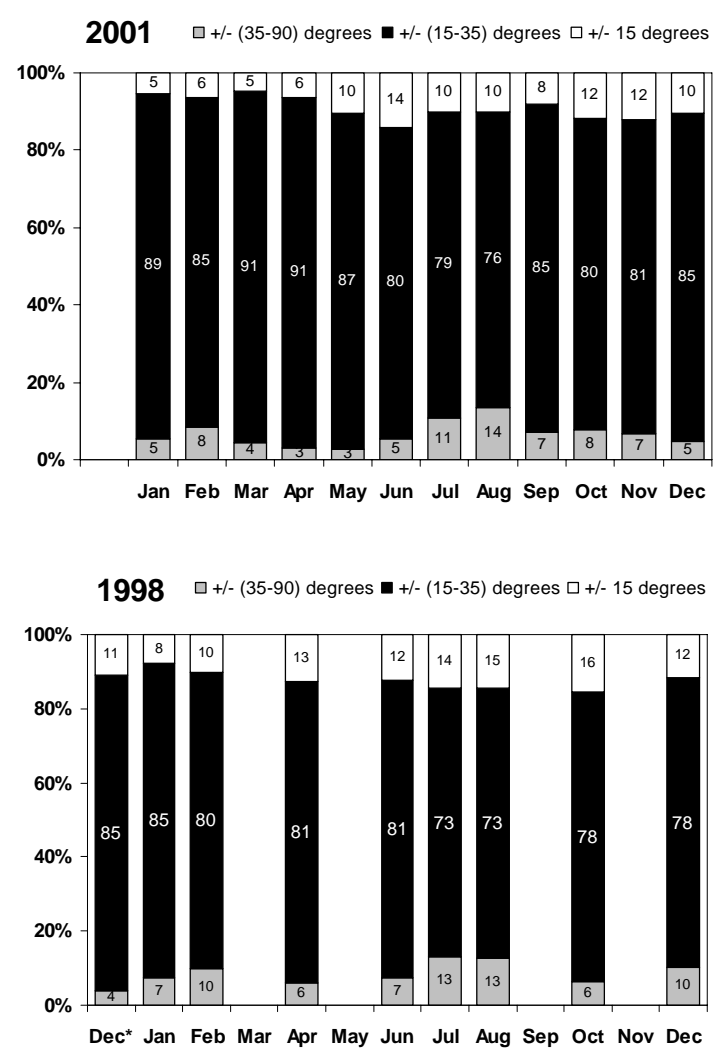

$1999 \square++$ - (35-90) degrees + +/ (15-35) degrees $\square+$ +/- 15 degrees

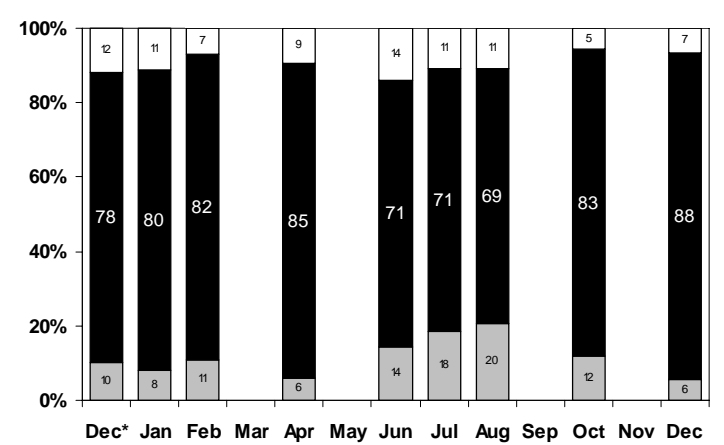

Fig. 2. The fraction of air parcels undergoing TST from the base of the TTL in each month of 2001 (baseline), 1998 (El Niño) and 1999 (La Niña) that enter the stratosphere (i.e. cross the tropopause) in the tropics between $\pm 15^{\circ}$ latitude, the subtropics between $\pm(15-35)^{\circ}$ latitude, and at higher latitudes between $\pm(35-90)^{\circ}$ latitude. NB Not all months in 1998 (middle panel) or 1999 (lower panel) were studied, however, the results for the preceding December (i.e. December 1997 and December 1998; labelled Dec*) are presented.

\section{Distribution of extratropical TST between the $\mathrm{NH}$ and the $\mathrm{SH}$}
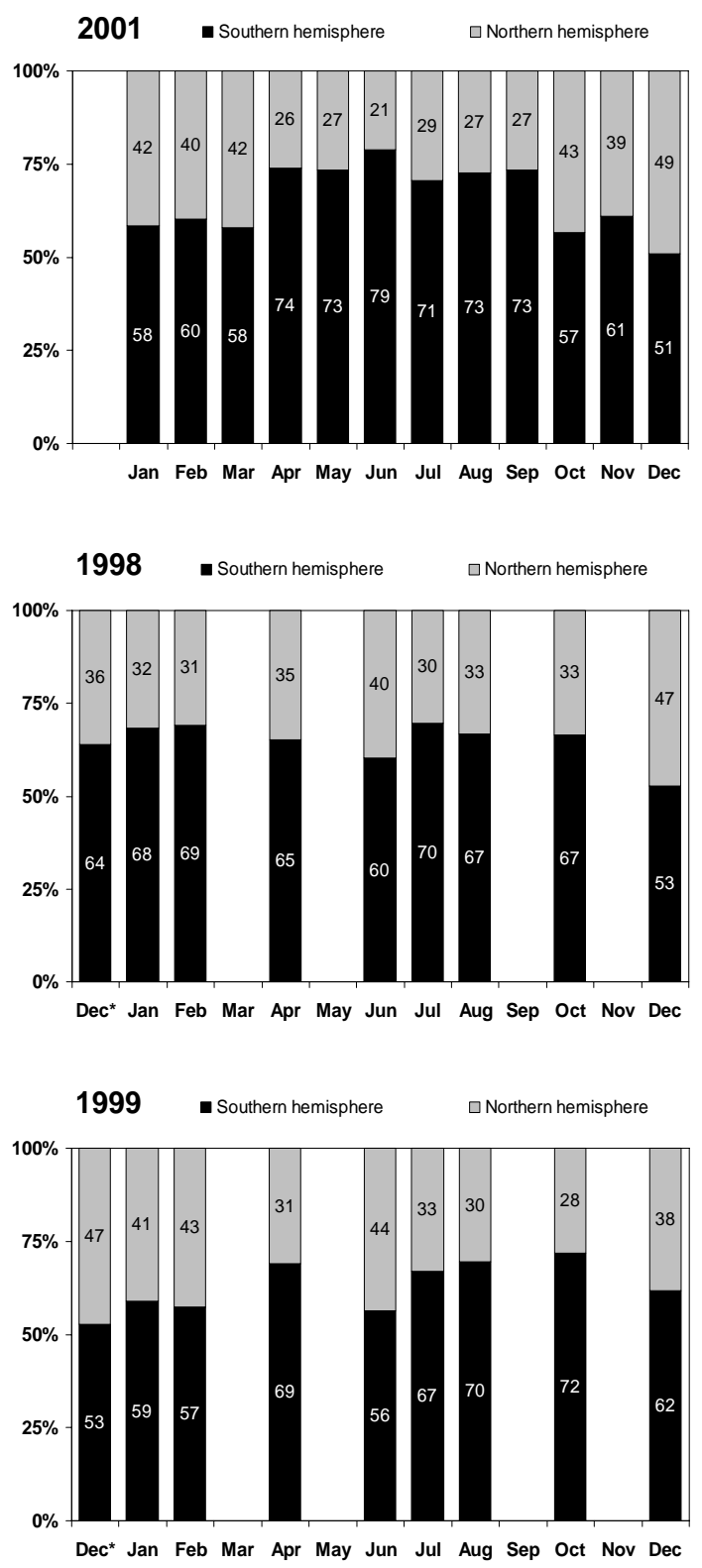

Fig. 3. The fraction of air parcels undergoing TST from the base of the TTL in each month of 2001 (baseline), 1998 (El Niño) and 1999 (La Niña) that enter the stratosphere (i.e. cross the tropopause) in the extratropics of the Northern Hemisphere $(\mathrm{NH})$ and the Southern Hemisphere (SH); see text for more details. NB Not all months in 1998 (middle panel) or 1999 (lower panel) were studied, however, the results for the preceding December (i.e. December 1997 and December 1998; labelled Dec*) are presented. 
3.3 The distribution of TST between the Northern and Southern Hemispheres

Until now, we have not differentiated between the air parcels that enter the stratosphere in the Northern Hemisphere (NH) and those that enter the stratosphere in the Southern Hemisphere $(\mathrm{SH})$. Figure 3 illustrates what fraction of the air parcels undergoing TST in each month of 2001, 1998 and 1999 enter the stratosphere in each hemisphere. Note that we have only included here those air parcels that enter the stratosphere in the extratropics (i.e. poleward of $\pm 15^{\circ}$ latitude); the patterns are near-identical when all air parcels crossing the tropopause are included. On the whole, more air enters the stratosphere in the SH than in the NH. The fraction of air that enters the stratosphere in the $\mathrm{SH}$ varies between about 50 and $75 \%$, however, there is not a single month (studied) in 2001, 1998 or 1999 in which more air enters the stratosphere in the NH than in the SH. In 2001, the hemispheric distribution of TST appears to exhibit an annual cycle between a fairly even distribution during the $\mathrm{NH}$ winter and one which is clearly skewed towards the SH during the NH summer. There is a suggestion of a similar cycle in 1999, however, no such cycle can be identified in 1998 .

We focus in the remainder of this section on the annual cycle identified in 2001 and, in particular, on how this cycle may be related to seasonal variations in the shape of the tropopause. Figure 4 illustrates the pressure/latitude cross-section of the tropopause in each month of 2001 (solid black line), superimposed by the distribution of TST across it (dashed black line); see Sect. 2 for the definition of the tropopause. During the NH winter (e.g. January), the shape of the tropopause in the subtropics is roughly symmetrical about the equator and a not-dissimilar fraction of air parcels enter the stratosphere in each hemisphere $(58 \%$ in the $\mathrm{SH}$ cf. $42 \%$ in the $\mathrm{NH}$ ). However, during the $\mathrm{NH}$ summer (e.g. July), neither the tropopause nor the distribution of TST is symmetrical about the equator. The tropopause (in the subtropics) is considerably lower in the SH than in the $\mathrm{NH}$ and many more air parcels enter the stratosphere in the $\mathrm{SH}(69 \%)$ than in the $\mathrm{NH}(31 \%)$. Evidently, at this time of the year, air parcels released at the base of the TTL $\left( \pm 19.5^{\circ}\right.$ latitude) are required to travel, on average, a shorter distance to reach the stratosphere in the SH. However, neither the concentration of TST in the subtropics nor the bias towards TST in the SH is simply a result of the short (horizontal) distance between the tropopause and the region in which the trajectories are released; trajectories originating close to the equator, between $\pm 9.5^{\circ}$ latitude, exhibit the same qualitative patterns (see Fig. 4; dotted black lines). By the end of 2001 (e.g. December, shown in Fig. 4), the symmetry of TST about the equator is re-established. We discuss the cause of this annual cycle and the overall bias towards TST in the SH further in Sect. 4.2.

\subsection{The longitudinal structure of TST}

Figure 5 illustrates what fraction of the air parcels undergoing TST in each month of 2001, 1998 and 1999 (a) come from each region of the TTL and (b) enter each region of the stratosphere; the TTL and the stratosphere are divided into $45^{\circ}$ intervals in longitude, with "Africa" spanning $0-45^{\circ}$, the "Indian Ocean" spanning $45-90^{\circ}$ and so on (see figure caption). To first order, irrespective of the season and year, an appreciable fraction of the air undergoing TST comes from each region of the TTL and enters each region of the stratosphere. To this extent, the homogeneity of TST from the base of the TTL identified in January 2001 (see Levine et al., 2007) proves robust to change of timing. However, some variations can be seen. For example, with the exception of a period at the beginning of 1998, larger-than-average fractions of the air undergoing TST come from the regions of the TTL above Indonesia (red) and the West Pacific (dark yellow); see Fig. 5a. At the beginning of 1998 (El Niño), less of the air comes from these regions of the TTL, whilst rather more comes from the regions above the East Pacific (light green) and South America (dark green); the shift from the West Pacific/Indonesia to the East Pacific/South America will be discussed in Sect. 4.4. As for the entry of air into the stratosphere, larger-than-average fractions of the air undergoing TST enter the stratosphere above Africa (dark blue), the Indian Ocean (purple), South America (dark green) and the Atlantic (bright blue), whilst smaller-than-average fractions enter above the West, Central and East Pacific regions (dark yellow, light yellow and light green respectively).

\subsection{The sensitivity of modelled TST to the definition of the tropopause}

Until now, we have exclusively studied TST with respect to the dynamical tropopause, defined throughout the extratropics as the level at which the potential vorticity, PV, is equal to 2 PV units; see Sect. 2. However, to explore the sensitivity of modelled TST to the definition of the tropopause, we have repeated some of our calculations using the thermal tropopause definition of the WMO (1957): the lowest level at which the temperature lapse rate rises above $-2 \mathrm{Kkm}^{-1}$, and the average lapse rate between this level and one $2 \mathrm{~km}$ above does not fall below $-2 \mathrm{Kkm}^{-1}$. Analogous to Fig. 4, Fig. 6 illustrates the pressure/latitude cross-section of the zonal-mean thermal tropopause in each month of 2001 (thick black line), superimposed by the distribution of TST across it (dashed black line). Much less TST is modelled with respect to the thermal tropopause, than with respect to the dynamical tropopause, within each four-week integration; note the change of scale between Figs. 4 and 6. From Fig. 6, we can see that the thermal tropopause (thick black line) lies above the dynamical tropopause (thin black line) throughout the extratropics. It is therefore possible that the reduction in TST at least partly reflects the increase in the average distance air parcels must 

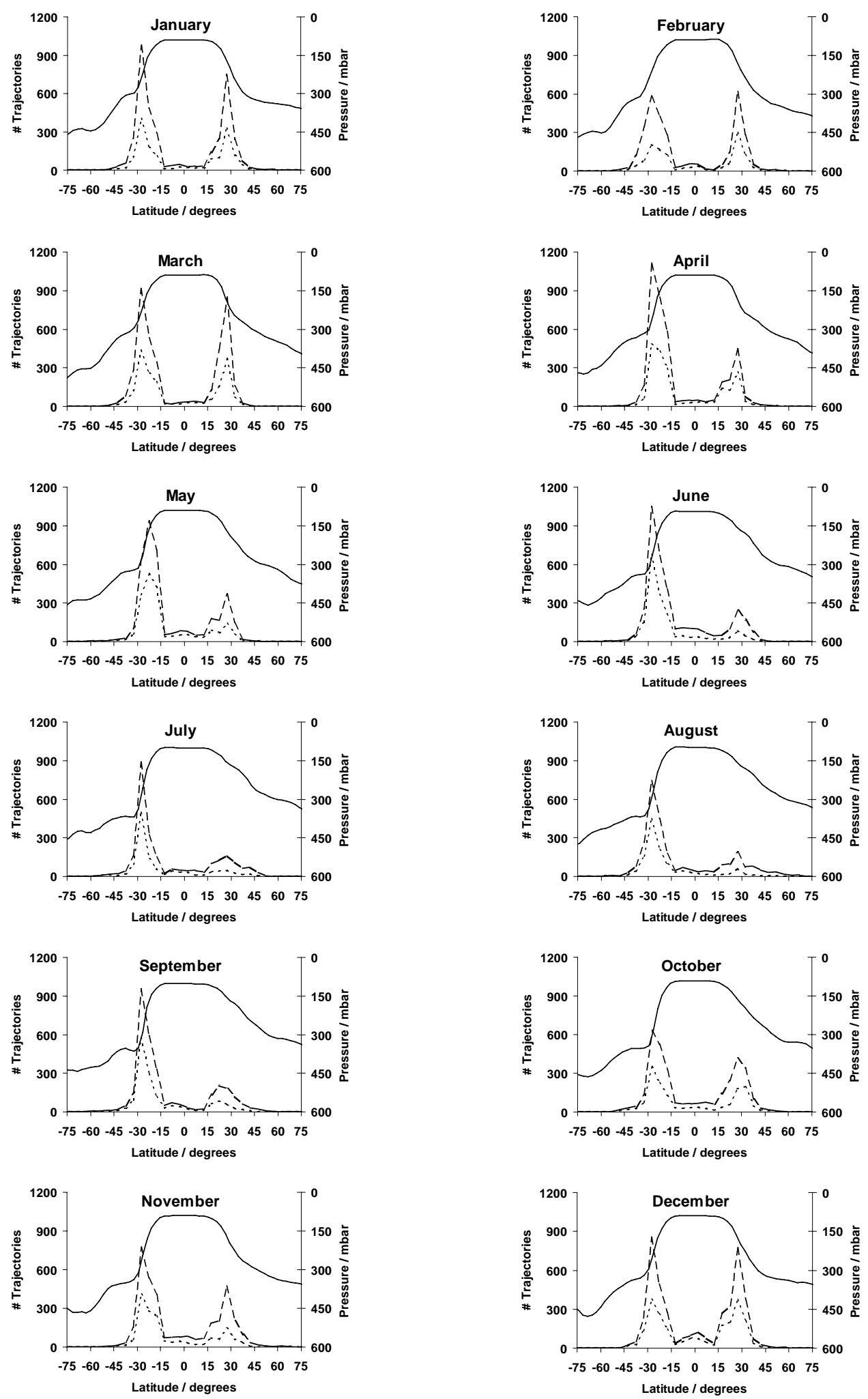

Fig. 4. The pressure/latitude cross-section of the zonal-mean, monthly-mean dynamical tropopause (solid black line), as defined in Sect. 2, superimposed by the frequency distribution of the latitudes $\left(5^{\circ}\right.$ bins) at which air parcels enter the stratosphere (i.e. cross the tropopause) in each month of 2001; the dashed black lines refer to air parcels released between $\pm 19.5^{\circ}$ latitude, whilst the dotted black lines refer to air parcels released between $\pm 9.5^{\circ}$ latitude. 


\section{(a) TTL origin of air parcels transported to the stratosphere}
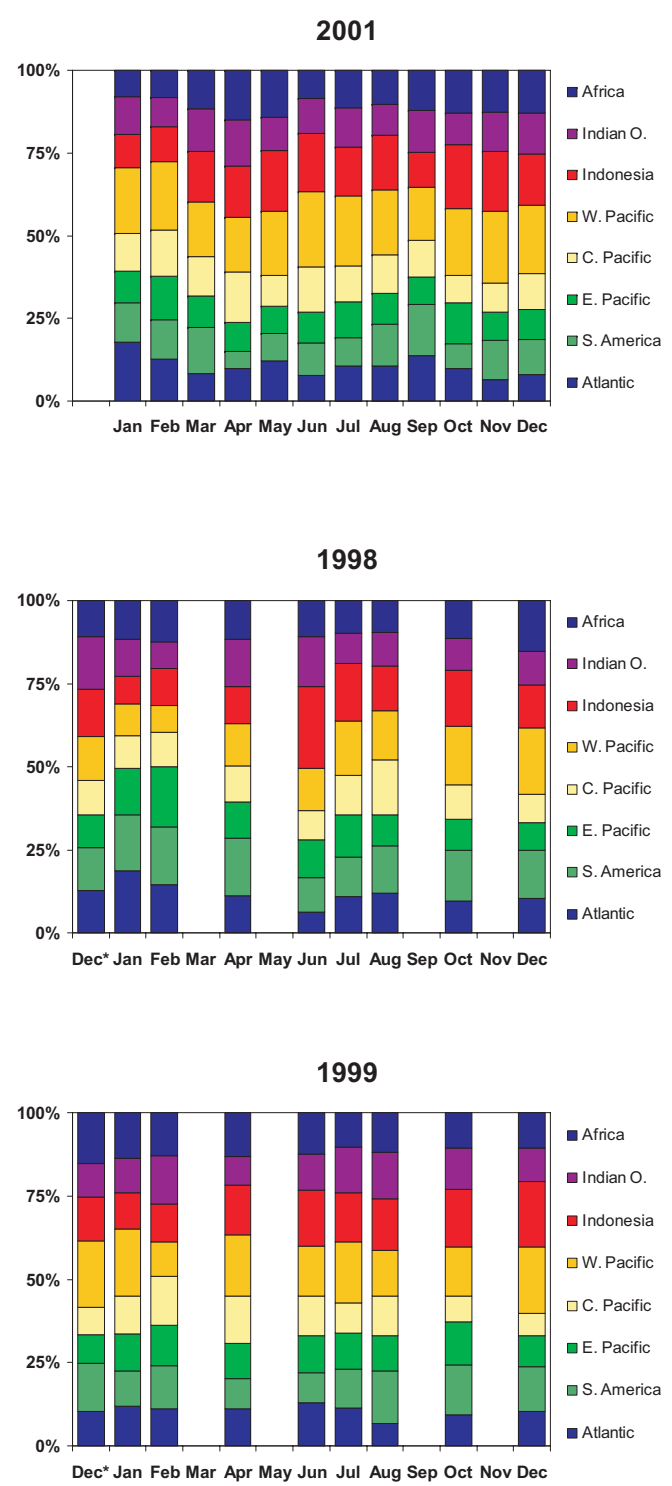

(b) Entry of air parcels into the stratosphere
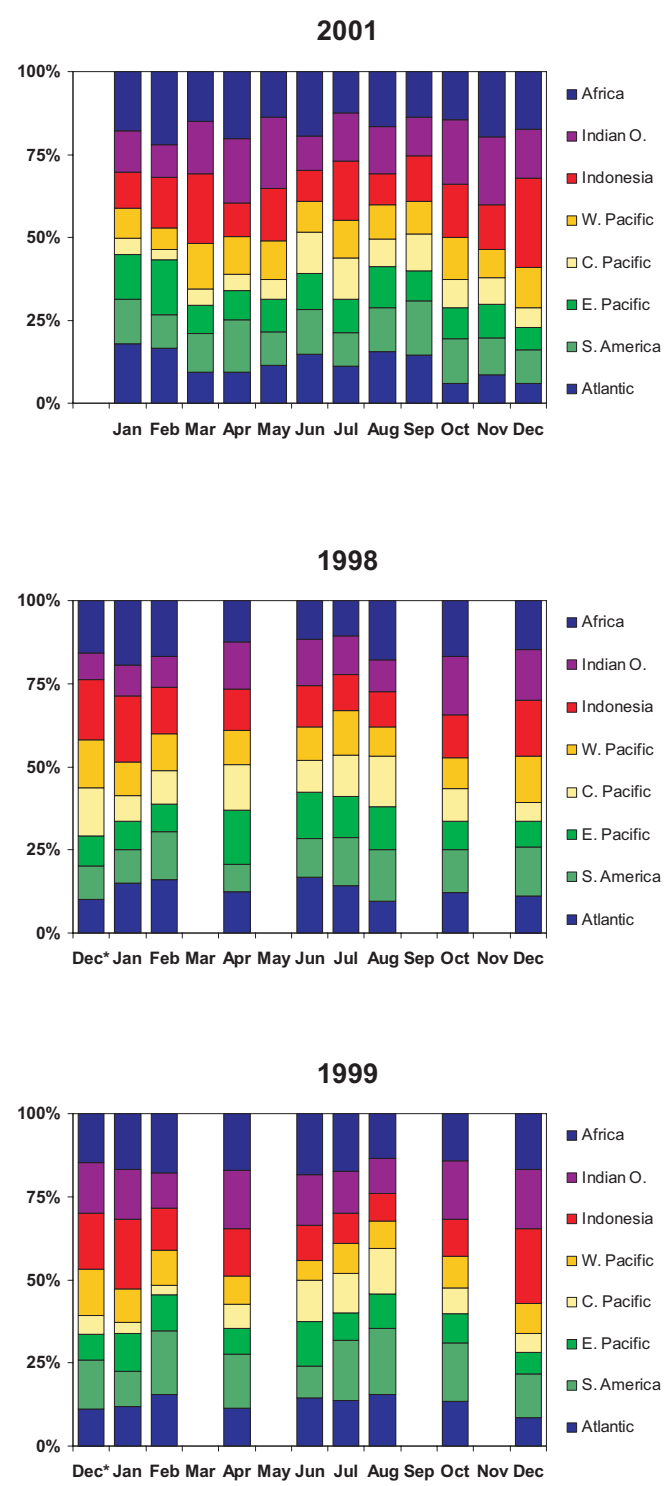

Fig. 5. The fraction of air parcels undergoing TST from the base of the TTL in each month of 2001 (baseline), 1998 (El Niño) and 1999 (La Niña) that (a) originate in each region of the TTL and (b) enter each region of the stratosphere; the TTL and the overworld are divided into $45^{\circ}$ intervals in longitude, with Africa $=0-45^{\circ}$, Indian Ocean $=45-90^{\circ}$, Indonesia $=90-135^{\circ}$, W. Pacific $=135-180^{\circ}, \mathrm{C}$. Pacific $=180-225^{\circ}, \mathrm{E}$. Pacific $=225-270^{\circ}$, S. America $=270-315^{\circ}$ and Atlantic $=315-360^{\circ}$. NB Not all months in 1998 (middle panel) or 1999 (lower panel) were studied, however, the results for the preceding December (i.e. December 1997 and December 1998; labelled Dec*) are presented.

travel, from the base of the TTL, to reach the stratosphere. The latitudinal distribution of TST also changes. Although roughly the same number of air parcels cross the tropopause in the tropics subject to either definition, many fewer air parcels cross the thermal tropopause in the subtropics.
3.6 The longitudinal structure of transport to the overworld

In the preceding sections, TST has included transport into the ELS and transport to the overworld. However, we focus in this section on transport exclusively to the overworld. Figure 7 illustrates what fraction of the air parcels undergoing transport to the overworld in each month of 2001, 1998 and 1999 (a) come from each region of the TTL and (b) 

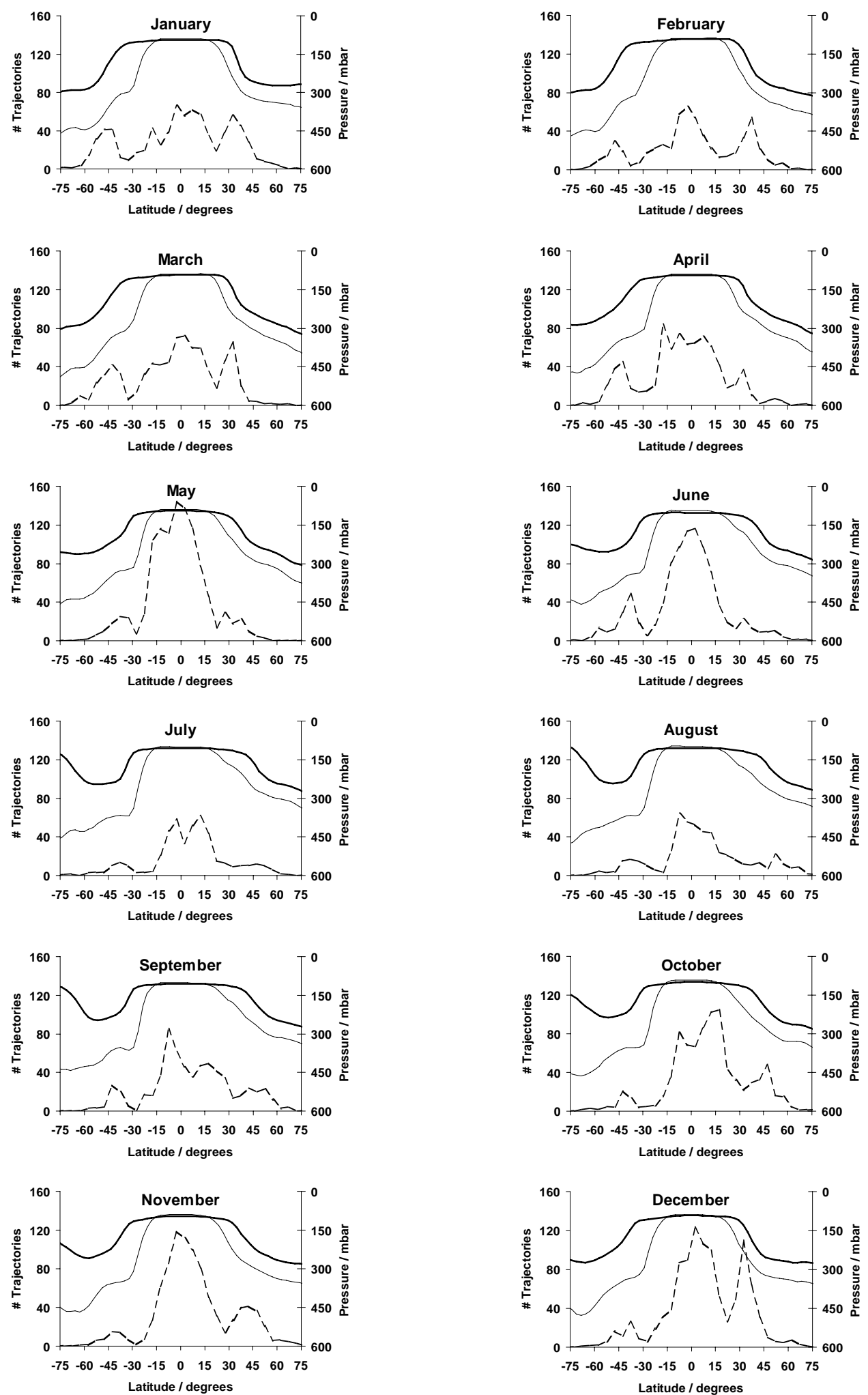

Fig. 6. The pressure/latitude cross-section of the zonal-mean, monthly-mean thermal tropopause (thick black line), as defined by the World Meteorological Organization (WMO, 1957), superimposed by the frequency distribution of the latitudes ( $5^{\circ}$ bins) at which air parcels enter the stratosphere (i.e. cross the tropopause) in each month of 2001 (dashed black line). For comparison, the zonal-mean dynamical tropopause, as defined in Sect. 2, is also illustrated in each month (thin black line). 
(a) TTL origin of air parcels transported to the overworld
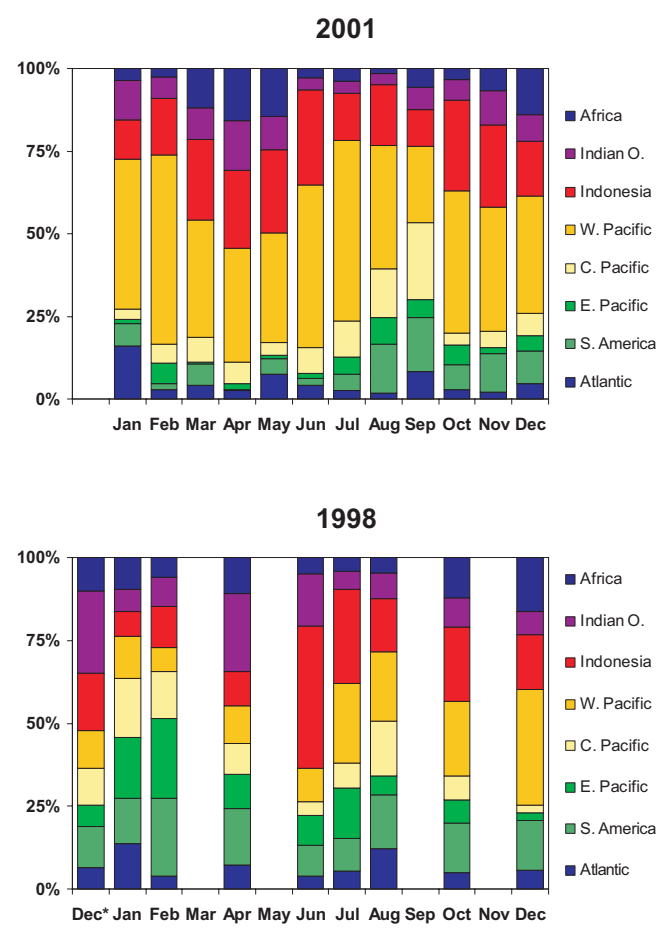

1999

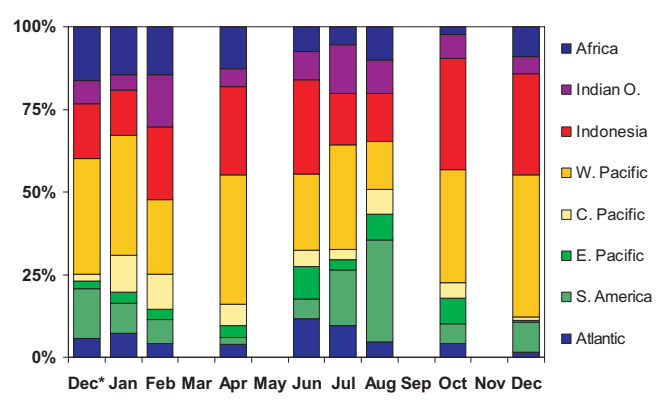

(b) Entry of air parcels into the

overworld

2001

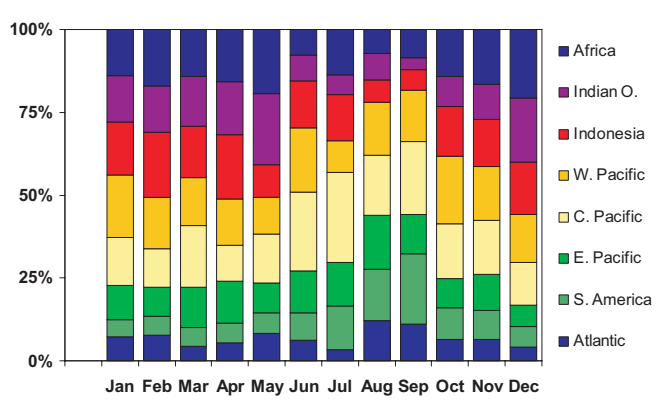

1998

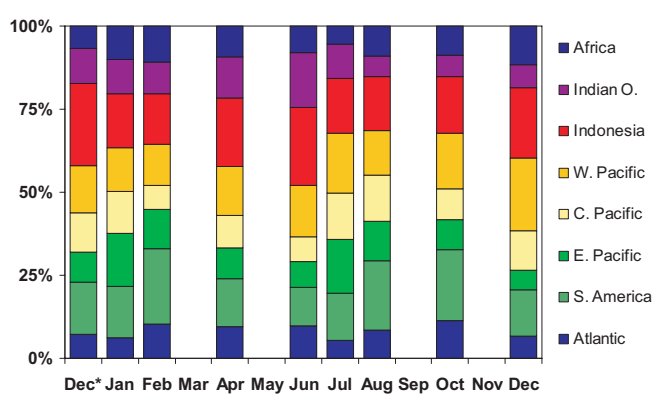

1999

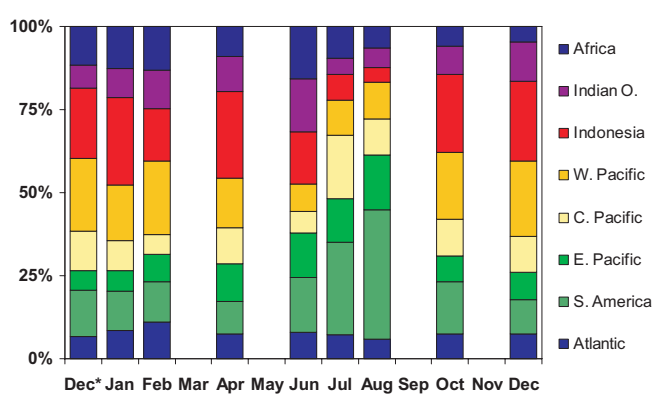

Fig. 7. The fraction of air parcels undergoing transport to the overworld from the base of the TTL in each month of 2001 (baseline), 1998 (El Niño) and 1999 (La Niña) that (a) originate in each region of the TTL and (b) enter each region of the overworld; the TTL and the overworld are divided into $45^{\circ}$ intervals in longitude, with Africa $=0-45^{\circ}$, Indian Ocean $=45-90^{\circ}$, Indonesia $=90-135^{\circ}, \mathrm{W}$. Pacific $=135-180^{\circ}$, C. Pacific $=180-225^{\circ}$, E. Pacific $=225-270^{\circ}$, S. America $=270-315^{\circ}$ and Atlantic $=315-360^{\circ}$. NB Not all months in 1998 (middle panel) or 1999 (lower panel) were studied, however, the results for the preceding December (i.e. December 1997 and December 1998 ; labelled Dec*) are presented.

enter each region of the overworld. The different longitudinal regions are the same as in Sect. 3.4. With the exception of a period at the beginning of 1998, a large fraction of the air transported to the overworld, between about 50 and $75 \%$, comes from the regions of the TTL above Indonesia (red) and the West Pacific (dark yellow); see Fig. 7a. Previous studies (e.g. Hatsushika and Yamazaki, 2003; Bonazzola and Haynes, 2004; Fueglistaler et al., 2004 and 2005) have identified the region of the TTL above the West Pacific as the predominant region for dehydration and the preferred origin of air reaching the overworld (as found here). However, at the beginning of 1998 (El Niño), we find that a much smaller fraction of the air comes from the regions above Indonesia and the West Pacific, whilst a larger fraction comes from the East Pacific (light green) and South America (dark green). The cause of this shift will be discussed further in Sect. 4.4. Other variations in the TTL origin of air transported to the overworld can be identified. It would appear 
that a larger fraction of the air comes from the region above South America (dark green) during the late summer/early autumn (e.g. August/September) than the rest of the year, at least in 2001 (baseline) and 1999 (La Niña); in 1998 (El Niño), this seasonality is obscured by the large fraction of air transported from the region above South America at the beginning of this year. Note that we have not assessed the statistical significance of these features.

On the whole, the entry of air into the overworld exhibits less longitudinal structure, with an appreciable fraction of air entering the overworld in each region; see Fig. 7b. However, that is not to say the same fraction of air enters each region of the overworld. In 2001, a larger-than-average fraction of air enters the overworld above the Central Pacific (light yellow), whilst a greater fraction of air enters above Indonesia (red) in 1998 and 1999. It would also appear that a larger fraction of air enters the overworld above South America (dark green) during the late summer/early autumn (e.g. August/September) than at any other time of the year.

\section{Summary and discussion}

In extending our earlier study (Levine et al., 2007) over several years, we have found that transport into the ELS consistently comprises the main route by which air undergoes TST from the base of the TTL. On timescales relevant to very short-lived species (less than or equal to four weeks), transport to the overworld typically accounts for less than $25 \%$ of total TST (transport into the ELS + transport to the overworld). However, besides supporting our earlier findings, the study of a variety of months and years has revealed seasonal variations in the amount of TST and the distribution of TST between the Northern and Southern Hemispheres; we will discuss these variations in Sects. 4.1 and 4.2 respectively. Of particular interest is the overall bias towards TST in the $\mathrm{SH}$ (integrated over a twelve-month period). We have also found that the amount of TST calculated in the subtropics is sensitive to the definition of the tropopause; see Sect. 4.3. Finally, following on from previous studies of transport to the overworld, we have examined the routes by which air parcels undergo transport to potential temperatures in excess of $380 \mathrm{~K}$. These air parcels mainly come from regions of the TTL above the West Pacific and Indonesia. However, we have identified a clear shift in the TTL origin of these air parcels to the East Pacific and South America during an El Niño period. In Sect. 4.4, we will show how this shift is related to changes in cloud cover and convection, accompanying changes in equatorial sea-surface temperatures, characteristic of an El Niño.

\subsection{The seasonality of TST}

Irrespective of the season and year, much more transport takes place into the ELS than into the overworld, as evidenced by the larger fraction of air parcels found in the ELS (roughly 10\%) than are found in the overworld (about 2\%) four weeks after release at the base of the TTL. We conclude that the dominance of transport into the ELS identified in January 2001 (see Levine et al., 2007) proves robust to change of timing. However, both the amount of transport into the ELS and the amount of transport into the overworld vary with season, exhibiting a maximum in the $\mathrm{NH}$ winter and a minimum in the NH summer; see Fig. 1.

Based on observations of ozone and water vapour in the mid-latitude lowermost stratosphere, Randel et al. (2001) and Prados et al. (2003) deduced that more TST takes place into the ELS during the NH summer than the NH winter. This seasonality appears to contrast with that which we have identified. However, the concentrations of trace gases in the ELS are sensitive not only to the amount of TST from the TTL, but to the amount of TST from the extratropical troposphere (Hoor et al., 2004 and 2005), which is not included in our calculations. Recall that we have used forward trajectories to investigate the routes by which air parcels undergo TST from the TTL. We do not calculate mass fluxes, only what fraction of air parcels in the TTL undergo TST. Furthermore, we cannot calculate what fraction of air parcels in the stratosphere come from the TTL as opposed, for example, to the extratropical troposphere or the overlying stratosphere (the overworld). Hoor et al. (2005) used in-situ observations of carbon monoxide in the northern lowermost stratosphere to calculate, as a function of season, what fraction of air in the ELS comes from the tropical troposphere (the TTL), the extratropical troposphere and the overlying stratosphere. They report that a larger fraction of air in the ELS comes from the tropical troposphere during the $\mathrm{NH}$ summer $(55 \%)$ than the $\mathrm{NH}$ winter (35\%). However, this is not equivalent to saying more TST takes place from the TTL during the NH summer than the NH winter. One possibility is that differences in our findings arise as a result of including shallow TST; see Sect. 3.1 for more details.

The seasonality in transport to the overworld, being greater in the $\mathrm{NH}$ winter than the $\mathrm{NH}$ summer, is consistent with the annual cycle in vertical velocities in the tropical lower stratosphere reported by Mote et al. (1996). Furthermore, the variations Mote et al. (1996) identified in the speed of the so-called atmospheric tape recorder are consistent with the mass-flux estimates of Rosenlof and Holton (1993) and Rosenlof (1995). The increase in transport to the overworld during the $\mathrm{NH}$ winter is attributed to the stronger wintertime Brewer-Dobson circulation arising from increased wave-driving in the northern mid-latitude stratosphere and mesosphere (e.g. Holton et al., 1995). 


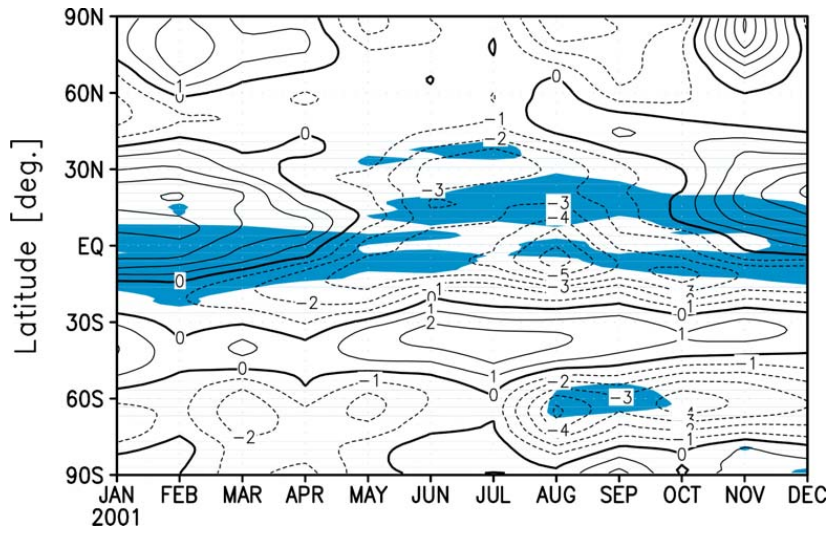

Fig. 8. The meridional velocity $(\bar{v})$ at the base of the TTL $(150 \mathrm{hPa})$, averaged over a region above and downwind of the West Pacific (45-180 $0^{\circ}$ longitude), plotted as a function of latitude and time in 2001; the solid contours indicate where air moves towards the north $(\bar{v}>0)$, whilst the dashed contours indicate where air moves towards the south $(\bar{v}<0)$. The blue regions indicate where the fastest ascent $(\bar{\omega}<-0.01 \mathrm{~Pa} / \mathrm{s})$ takes place, averaged over the region above the West Pacific (135-180 $0^{\circ}$ longitude). The data are taken from the ERA-40 analyses of the European Centre for Medium-range Weather Forecasts. See text for further details.

\subsection{Hemispheric asymmetries in TST}

Averaged over each of the three years studied (2001, 1998 and 1999), between 60 and $65 \%$ of the air parcels undergoing TST enter the stratosphere in the SH; see Fig. 3. In 2001, and arguably in 1999, the hemispheric distribution of TST exhibits an annual cycle between a fairly even distribution during the $\mathrm{NH}$ winter and one which is skewed towards the $\mathrm{SH}$ during the NH summer. No such cycle can be identified in 1998 - the El Niño year. To understand the seasonality of TST and the overall bias towards TST in the SH, we have explored variations in the shape of the dynamical tropopause. In all three years, the shape of the zonal-mean tropopause is symmetric about the equator during the $\mathrm{NH}$ winter, whilst a considerably lower tropopause is diagnosed in the subtropics of the $\mathrm{SH}$, compared to the $\mathrm{NH}$, during the $\mathrm{NH}$ summer; see Fig. 4. Appenzeller et al. (1996) identified a similar cycle.

Another related source of seasonal and hemispheric differences in TST is the annual cycle in large-scale winds. Here, we describe the annual cycle of averaged vertical $(\bar{\omega})$ and meridional velocities ( $\bar{v}$ ) (Fig. 8) to characterise the large-scale (Eulerian) dynamical setup of the circulation in which the individual (Lagrangian) air parcel trajectories are embedded. ERA-40 data are used for the description of time-averaged large-scale dynamics, even though the trajectories were calculated using the 6-hourly operational analyses of the ECMWF. For the features we highlight, the agreement between ERA-40 and operational analyses is more than adequate and additional climatological information can be obtained from the ERA-40 Atlas (http://www.ecmwf. int/publications/library/do/references/show?id=86620). Our analysis focuses on the $150 \mathrm{hPa}$ level - approximately the base of the TTL.

In Fig. 8, the regions of fastest ascent at $150 \mathrm{hPa}$ (zonally averaged between 135 and $180^{\circ}$ longitude and defined by $\bar{\omega}<-0.01 \mathrm{~Pa} / \mathrm{s}$ ) are shaded blue. Pronounced regions of ascent are found $5-10^{\circ}$ north of the equator during the $\mathrm{NH}$ summer and $5-10^{\circ}$ south of the equator during the $\mathrm{NH}$ winter. The isolines in Fig. 8 show meridional velocities $(\bar{v})$ at the same level, averaged over a somewhat broader region above, and downwind of, the West Pacific (between 45 and $180^{\circ}$ longitude). Note the relative positions of the regions of strongest ascent and the regions in which air is predominantly transported to the north (solid contours) and south (dashed contours). During the NH summer, southward velocities are predominantly encountered in the region of strongest ascent, whereas during the $\mathrm{NH}$ winter, a mixture of northward and southward velocities is encountered. This may be indicative of ascending air parcels standing a higher probability of undergoing transport to the south during the $\mathrm{NH}$ summer, in contrast to more similar probabilities of transport to the north and to the south during the $\mathrm{NH}$ winter.

The onset of the Indian summer monsoon in June is a major contributor to the seasonality exhibited by the longitudinally-averaged meridional velocities illustrated in Fig. 8 and, hence, contributes to our heuristic explanation of the bias in TST towards the SH. However, no distinct monsoon signature is evident from our transport diagnostics. Our trajectories originate at the base of the TTL, within a latitude band south of the monsoon area. We thus examine where air from the TTL enters the stratosphere. The use of backward trajectories initialised in the stratosphere, used to examine where air in the stratosphere comes from in the troposphere (e.g., most recently, Berthet et al., 2007), will provide independent, complementary information.

The discussion of the annual cycle in meridional velocities does mirror the annual cycle as depicted by an isentropic mass-weighted meridional streamfunction (see ERA-40 Atlas (http://www.ecmwf.int/publications/library/ do/references/show?id=86620) and Juckes et al., 1994 for the relation to the transformed-Eulerian mean (TEM) formalism). In comparison to the long term averaged ERA40 Atlas streamfunction, the seasonality in $\bar{v}$ as illustrated in Fig. 8 is more pronounced, partly due to the fact that $\bar{v}$ is only averaged over a certain range of longitudes and partly due to interannual variability; the interannual variability in the streamfunction is of the order of $10-20 \%$ in this region. In addition, zonally averaged vertical velocities around the equator are not expected to differ significantly from the residual mean vertical velocities as defined in the TEM formalism (Garcia et al., 2007). Undoubtedly, caution is paramount as we combine the Eulerian and Lagrangian frameworks of tropical motion in a heuristic explanation of trajectory behaviour. It is nevertheless safe to say the region of maximum ascent changes position (latitude) relative to the region 
of strongest meridional motion and the prevalent meridional wind direction changes as a function of season, with implications for the sideways transport modelled.

Two model studies (Chen, 1995; Dethof et al., 2000) have previously examined the hemispheric distribution of TST from the tropical upper troposphere into the ELS, including how it varies with season. Chen (1995) used a two-dimensional isentropic transport model to investigate transport between the troposphere and the stratosphere during 1993. Integrations using a tropical tracer at $350 \mathrm{~K}$ indicated that more TST took place in the $\mathrm{NH}$ during the NH summer. Using a contour advection technique, Dethof et al. (2000) studied the seasonality of troposphereto-stratosphere (TS) and stratosphere-to-troposphere (ST) mass fluxes on isentropic surfaces across the dynamical tropopause in 1997/1998. Notably, no pronounced seasonality in the NH was found at $345 \mathrm{~K}$, but the ST mass flux in the SH did show a maximum at this level in September. The tropically-confined release region we have chosen has its lowermost boundary at around $345 \mathrm{~K}$ and extends upwards; see Fig. 9. The seasonality we identify in Fig. 3 shows a pronounced hemispheric asymmetry similar to that apparent in Dethof et al. (2000) at $345 \mathrm{~K}$ (see Fig. 5 of Dethof et al., 2000) but seems to conflict with the findings of Chen (1995).

To unravel the apparent inconsistency, we analyse the vertical position of the $350 \mathrm{~K}$ surface during 2001; see Fig. 9. The relative position of isentropic surfaces with respect to pressure surfaces shows a pronounced annual cycle and the location in which a chosen isentropic surface (e.g. $350 \mathrm{~K}$ ) intersects the tropopause varies significantly in the $\mathrm{NH}$, with the $350 \mathrm{~K}$ surface intersecting the dynamical tropopause at higher pressures during the $\mathrm{NH}$ summer than the $\mathrm{NH}$ winter. In conjunction, strong sub- to extra-tropical meridional PV gradients (blue shading in Fig. 9) exist in both hemispheres along the tropopause (see e.g., Hitchman and Huesmann, 2007). The PV gradients are to some extent indicative of meridional transport barriers and show pronounced asymmetries between the two hemispheres. For example, maximum values of scaled monthly mean PV gradients on pressure surfaces are always larger in the $\mathrm{NH}$ than the $\mathrm{SH}$ at $150 \mathrm{hPa}$, during 2001. Recall that our experiments probe the tropical region with a narrow one-off release of threedimensional trajectories from the base of the TTL (around $345 \mathrm{~K}$ ) in hybrid-pressure space, whereas previous experiments (e.g. Chen, 1995) used advection on isentropic surfaces. The perceived effectiveness of meridional transport barriers around and above $345 \mathrm{~K}$ or $200 \mathrm{hPa}$ will depend on where surfaces of constant pressure or potential temperature lie relative to the areas of strong PV gradients and might therefore differ significantly between methods. The relatively small size of the PV gradient feature, its 3-D structure and the shallow nature of the TTL highlight the importance for future studies of modelling transport at higher spatial resolutions in order to accurately quantify transport through this region.

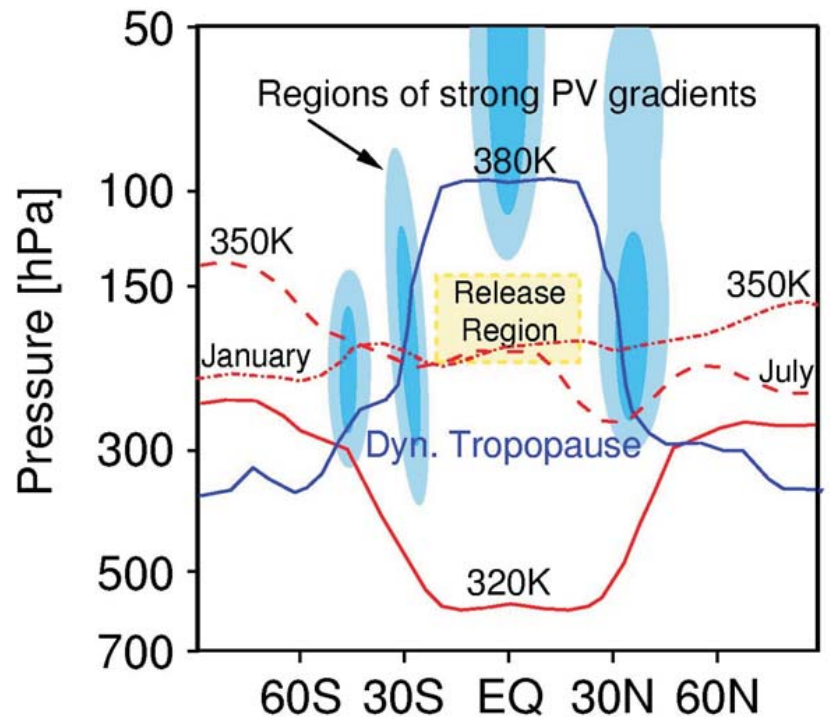

Fig. 9. Schematic to illustrate the position of the $350 \mathrm{~K}$ isentrope relative to the regions of strong potential vorticity $(\mathrm{PV})$ gradients (blue shading) encountered at, or close to, the dynamical tropopause in January and July 2001. NB The dynamical tropopause is defined as the level at which the potential vorticity, PV, is equal to $2 \mathrm{PV}$ units throughout the extratropics; the tropical tropopause is defined as the level of minimum temperature (cold point) that closely coincides with the $380 \mathrm{~K}$ isentrope.

\subsection{The definition of the tropopause}

We have mostly quantified TST with respect to the dynamical tropopause, defined throughout the extratropics as the level at which the potential vorticity, PV, is equal to $2 \mathrm{PV}$ units. We have done so because, ultimately, our motivation stems from the potential for halogenated very short-lived species to contribute to the depletion of ozone in the lowermost stratosphere and the concentration of ozone is observed to increase rapidly with increasing altitude above the 2 PV unit level (e.g. Hegglin et al., 2006; Thouret et al., 2006). The main difference on switching from this definition of the tropopause to the thermal definition proposed by the WMO (1957) is that much less TST is modelled in the subtropics; compare Figs. 4 and 6. Our results suggest that studies of TST with respect to the thermal tropopause will significantly underestimate the amount of transport into the region characterised by typically stratospheric ozone concentrations. We therefore concur with Hegglin et al. (2006) and Thouret et al. (2006) that the dynamical tropopause definition is most appropriate for chemical studies, particularly those related to ozone. The choice of definition could also have implications for the amount of transport modelled from the stratosphere into the troposphere, relevant to tropospheric ozone budget assessments. 

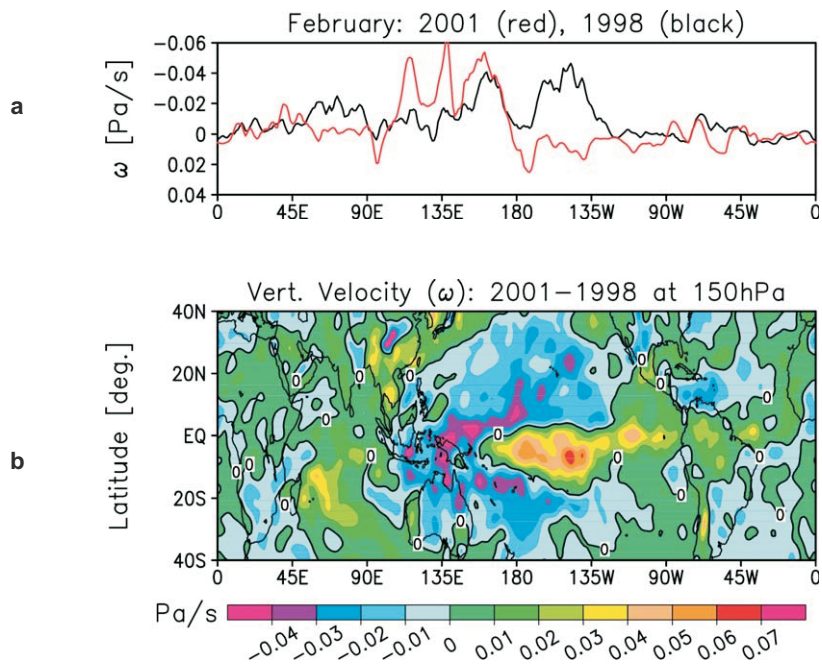

Fig. 10. (a) The vertical velocity $(\omega)$ at $150 \mathrm{hPa}$, averaged between $5^{\circ} \mathrm{N}$ and $15^{\circ} \mathrm{S}$, plotted as a function of longitude in February 2001 (red line) and February 1998 (black line). (b) The difference between the vertical velocities $(\omega)$ at $150 \mathrm{hPa}$ in February 1998 and February 2001 plotted as a function of latitude and longitude; the orange and red regions indicate where faster ascent (or slower descent) takes place in February 1998 relative to February 2001, whilst the blue and purple regions indicate where slower ascent (or faster descent) occurs. The data are taken from the ERA-40 analyses of the European Centre for Medium-range Weather Forecasts.

\subsection{Routes of transport to the overworld}

Our calculations suggest the routes by which air parcels undergo transport to the overworld contrast with those of transport into the ELS (the main route by which TST takes place) described in Sect. 3.4. Throughout 2001 (baseline) and 1999 (La Niña), between 70 and $90 \%$ of the air undergoing transport to the overworld comes from the regions of the TTL above Indonesia and the West Pacific; see Fig. 7a. However, at the beginning of 1998 (El Niño), much of the air comes not from these regions of the TTL, but from those above the East Pacific and South America. In Sect. 4.2, we identified a similar shift, albeit less pronounced, with regards to the TTL origin of air undergoing TST (i.e. including transport into the ELS). In an effort to explain these changes, we have again examined the large-scale ERA-40 wind fields. Zonal averaging conceals the longitudinal structure in the vertical velocities encountered close to the base of the TTL $(150 \mathrm{hPa})$. Figure 10a illustrates the monthly-mean vertical velocity at this level, averaged between $5^{\circ} \mathrm{N}$ and $15^{\circ} \mathrm{S}$, as a function of longitude in February 2001 (red line) and February 1998 (black line). We can see that in 2001, the fastest ascent takes place between about 100 and $170^{\circ} \mathrm{E}$, broadly above Indonesia and the West Pacific; similar patterns are observed in 1999. In 1998, the fastest ascent occurs further east, between about $150^{\circ} \mathrm{E}$ and $120^{\circ} \mathrm{W}$, above the Central and East Pacific. We can thus explain an eastward shift in the predominant origin of air undergoing transport to the overworld and, hence, TST. The difference in vertical velocities at the base of the TTL, between February 2001 and February 1998, is illustrated as a function of latitude and longitude in Fig. 10b; the orange and red regions indicate where faster ascent (or slower descent) takes place in 1998 (El Niño) relative to 2001 (baseline). The increase in rates of ascent above the Central and East Pacific is consistent with an increase in total- and high cloud cover in this region modelled by the ECMWF. We can thus link the change we have identified in the TTL origin of air transported to the overworld to changes in convection and vertical velocities resulting from changes in equatorial sea surface temperatures characteristic of an El Niño (the warming of the equatorial Pacific towards South America).

Acknowledgements. This is a contribution to the EU Integrated Project SCOUT-O3; we gratefully acknowledge the support of the EU. The work was also supported by the NERC-funded National Centre for Atmospheric Science (NCAS) and JGL gratefully acknowledges an e-science studentship, provided by the NERC. Finally, we are grateful to John Methven for his continuing support in using the trajectory code, Offline 3.

Edited by: M. Dameris

\section{References}

Allam, R. J. and Tuck, A. F.: Transport of water vapour in a stratosphere-troposphere general circulation model. I: Fluxes, Q. J. R. Meteorol. Soc., 110, 321-356, 1984.

Appenzeller, C., Holton, J. R., and Rosenlof, K. H.: Seasonal variation of mass transport across the tropopause, J. Geophys. Res. 101(D10), 15 071-15078, 1996.

Bethan, S., Vaughan, G., and Reid, S. J.: A comparison of ozone and thermal tropopause heights and the impact of tropopause definition on quantifying the ozone content of the troposphere, Q. J R. Meteorol. Soc., 122, 929-944, 1996.

Berthet, G., Esler, J. G., and Haynes, P. H.: A lagrangian perspective of the tropopause and the ventilation of the lowermost stratosphere, J. Geophys. Res., 112, D18102, doi:10.1029/2006JD008295, 2007.

Bonazzola, M. and Haynes, P. H.: A trajectory-based study of the tropical tropopause region, J. Geophys. Res., 109, D20112, doi:10.1029/2003JD004356, 2004.

Chandra, S., Ziemke, J. R., Min, W., and Read, W. G.: Effects of 1997-1998 El Nino on tropospheric ozone and water vapour, Geophys. Res. Lett., 25(20), 3867-3870, 1998.

Chen, P.: Isentropic cross-tropopause mass exchange in the extratropics, J. Geophys. Res., 100(D8), 16 661-16673, 1995.

Dethof, A., O'Neill, A., and Slingo, J.: Quantification of the isentropic mass transport across the dynamical tropopause, J. Geophys. Res., 105, 12 279-12 293, 2000.

Fueglistaler, S., Wernli, H., and Peter, T.: Tropical troposphereto-stratosphere transport inferred from trajectory calculations, J. Geophys. Res., 109, D03108, doi:10.1029/2003JD004069, 2004. 
Fueglistaler S., Bonazzola, M., Haynes, P. H., and Peter, T.: Stratospheric water vapor predicted from the Lagrangian temperature history of air entering the stratosphere in the tropics, J. Geophys. Res., 110, D08107, doi:10.1029/2004JD005516, 2005.

Garcia, R. R., Marsh, D. R., Kinnison, D. E., Boville, B. A., and Sassi, F., Simulation of secular trends in the middle atmosphere, 1950-2003, J. Geophys. Res., 112, D09301, doi:10.1029/2006JD007485, 2007.

Hatsushika, H. and Yamazaki, K.: Stratospheric drain over Indonesia and dehydration within the tropical tropopause layer diagnosed by air parcel trajectories, J. Geophys. Res., 108(D19), 4610, doi:10.1029/2002JD002986, 2003.

Hegglin, M. I., Brunner, D., Peter, T., Hoor, P., Fischer, H., Staehelin, J., Krebsbach, M., Schiller, C., Parchatka, U., and Weers, U.: Measurements of $\mathrm{NO}, \mathrm{NO}_{\mathrm{y}}, \mathrm{N}_{2} \mathrm{O}$ and $\mathrm{O}_{3}$ during SPURT: implications for transport and chemistry in the lowermost stratosphere, Atmos. Chem. Phys., 6, 1331-1350, 2006, http://www.atmos-chem-phys.net/6/1331/2006/.

Hitchman, M. H. and Huesmann, A. S.: A Seasonal Climatology of Rossby Wave Breaking in the 320-2000-K Layer, J. Atmos. Sci., 64, 1992-1940, 2007.

Hoerling, M. P., Schaack, T. K., and Lenzen, A. J.: A Global Analysis Of Stratospheric-Tropospheric Exchange During Northern Winter, Mon. Weather Rev., 121, 162-172, 1993.

Holton, J. R., Haynes, P. H., McIntyre, M. E., Douglass, A. R., Rood, R. B., and Pfister, L.: Stratosphere-troposphere exchange, Rev. Geophys., 33, 4, 403-439, 1995.

Hoor, P., Gurk, C., Brunner, D., Hegglin, M., Wernli, H., and Fischer, H.: Seasonality and extent of extratropical TST derived from in-situ CO measurements during SPURT, Atmos. Chem. Phys., 4, 1427-1442, 2004, http://www.atmos-chem-phys.net/4/1427/2004/.

Hoor, P., Fischer, H., and Lelieveld, J.: Tropical and extratropical tropospheric air in the lowermost stratosphere over Europe: A CO-based budget, Geophys. Res. Lett., 32, L07802, doi:10.1029/2004GL022018, 2005.

James, P., Stohl, A., Forster, C., Eckhardt, S., Seibert, P., and Frank, A., A 15-year climatology of stratosphere-troposphere exchange with a Lagrangian particle dispersion model: I. Methodology and validation, J. Geophys. Res., 108, 8519, doi:10.1029/2002JD002637, 2003.

Juckes, M. N., James, I. N., and Blackburn, M., The influence of Antarctica on the momentum budget of the southern extratropics, Q. J. R. Meteorol. Soc., 120, 1017-1044, 1994.

Levine, J. G., Braesicke, P., Harris, N. R. P., Savage, N. H., and Pyle, J. A.: Pathways and timescales for troposphere-tostratosphere transport via the tropical tropopause layer and their relevance for very short lived substances, J. Geophys. Res., 112, D04308 doi:10.1029/2005JD006940, 2007.

Methven, J.: Offline Trajectory Package, UGAMP Technical Report 34, Department of Meteorology, University of Reading, United Kingdom, 1997.
Mote, P. W., Rosenlof, K. H., Holton, J. R., Harwood, R. S., and Waters, J. W.: Seasonal variation of water vapor in the tropical lower stratosphere, Geophys. Res. Lett., 22, 1093-1096, 1995.

Mote, P. W., Rosenlof, K. H., McIntyre, M. E., Carr, E. S., Gille, J. C., Holton, J. R., Kinnersley, J. S., Pumphrey, H. C., Russell, J. M. III, and Waters, J. W.: An atmospheric tape recorder: The imprint of tropical tropopause temperatures on stratospheric water vapor, J. Geophys. Res., 101(D2), 3989-4006, 1996.

O'Connor, F. M., Vaughan, G., and Backer, H. De: Observations of subtropical air in the European mid-latitude lower stratosphere, Quart. J. Roy. Meteorol. Soc., 125(560), 2965-2986, 1999.

Prados, A. I., Nedoluha, G. E., Bevilacqua, R. M., Allen, D. R., Hoppel, K. W., and Marenco, A.: POAM III ozone in the upper troposphere and lowermost stratosphere: Seasonal variability and comparisons to aircraft observations, J. Geophys. Res., 108(D7), 4218, 2003.

Randel, W. J., Wu, F., Gettelman, A., Russell, J. M. III, Zawodny, J. M., and Oltmans, S. J.: Seasonal variation of water vapor in the lower stratosphere observed in Halogen Occultation Experiment data, J. Geophys. Res., 106(D13), 14 313-14 325, 2001.

Rosenlof, K. H. and Holton, J. R.: Estimates of the stratospheric residual circulation using the downward control principle, J. Geophys. Res., 98(D6), 10 465-10 479, 1993.

Rosenlof, K. H.: Seasonal cycle of the residual mean meridional circulation in the stratosphere, J. Geophys. Res., 100(D3), 51735191, 1995.

Thouret, V., Cammas, J.-P., Sauvage, B., Athier, G., Zbinden, R., Nédélec, P., Simon, P., and Karcher, F.: Tropopause referenced ozone climatology and inter-annual variability (1994-2003) from the MOZAIC programme, Atmos. Chem. Phys., 6, 1033-1051, 2006 , http://www.atmos-chem-phys.net/6/1033/2006/.

Vaughan, G., and Timmis, C.: Transport of near-tropopause air into the lower midlatitude stratosphere, Quart. J. Roy. Meteorol. Soc., 124(549), 1559-1578, 1998.

Wernli, H. and Bourqui, M.: A Lagrangian "1-year climatology" of (deep) cross-tropopause exchange in the extratropical Northern Hemisphere, J. Geophys. Res., 107, 4021, doi:10.1029/2001JD000,812, 2002.

Wirth, V.: Thermal versus dynamical tropopause in uppertropospheric balance flow anomalies, Q. J. R. Meteorol. Soc., 126, 299-317, 2000.

World Meteorological Organisation (WMO): Meteorology - a three-dimensional science, WMO Bull., 6, 134-138, 1957.

Zeng, G. and Pyle, J. A.: Influence of El Niño Southern Oscillation on stratosphere/troposphere exchange and the global tropospheric ozone budget, Geophys. Res. Lett., 32, L01814, doi:10.1029/2004GL021353, 2005.

Ziemke, J. R. and Chandra, S.: La Niña and El Niño-induced of ozone in the tropical lower atmosphere during 1970-2001, Geophys. Res. Lett., 30(3), 1142, 2003. 